Research Article

\title{
Impact of laser therapy added to non-surgical therapy in non-insulin dependent diabetic Saudi patients with chronic periodontitis
}

\begin{abstract}
Background: Chronic periodontitis (CP) is a common medical problem associated with non-insulin dependent diabetes mellitus (NIDDM) that affects about $47 \%$ of adult worldwide. The conventional therapy of $\mathrm{CP}$ is scaling and root planning (SRP). Although $\mathrm{SRP}$ is the golden therapy for $\mathrm{CP}$, it cannot eliminate the whole bacteria within periodontal tissues. Therefore, the need for innovative adjunct therapy for effective management of $\mathrm{CP}$
\end{abstract}

Objective: Our study aimed to assess the value of LILT added to SRP upon periodontal inflammation in NIDDM Saudi patients with CP.

Material and methods: Forty six NIDDM Saudi patients with chronic periodontitis (25 men and 21 women), their age ranged from $31-58$ year (mean $41.2 \pm 5.17$ year) participated in the study. The participants randomly divided between 2 equal groups. Group (A) received conventional treatment for $\mathrm{CP}$ that composed of scaling and root planing (SRP group); while Group (B) received low intensity laser therapy conventional treatment for CP (SRP+LILT group).

Results: Mean values of IL-6, TNF- $\alpha$, HBA1c, Plaque index, Probing pocket depth and gingival index reduced significantly after treatment in both groups. However, comparison between both groups after treatment revealed significant differences between group (A) and group (B). Moreover, group (B) received SRP+LILT gained greater reduction in the measured parameters.

Conclusion: Low intensity laser therapy as an effective adjunct to periodontal therapy upon periodontal inflammation in NIDDM Saudi patients with CP.

Keywords: periodontal therapy, non-insulin dependent diabetes mellitus, chronic periodontitis, low intensity laser therapy
Volume 10 Issue 6 - 2019

\author{
Fadwah M Al-Sharif,' Shereen O Al-jiffri² \\ 'Department of Medical Laboratory Technology, Faculty of \\ Applied Medical Sciences, King Abdulaziz University, Saudi Arabia \\ 2University Dental Hospital, King Abdulaziz University, Saudi \\ Arabia
}

Correspondence: Fadwah M Al-Sharif, Department of Medical Laboratory Technology, Faculty of Applied Medical Sciences, King Abdulaziz University, P.O. Box 80324, Jeddah, 21589,Saudi Arabia, Emaildrfadwa@gmail.com

Received: December 10, 2019 | Published: December 18, 2019
Abbreviations: SRP, scaling and root planning; CP, chronic periodontitis; NIDDM, non-insulin dependent diabetes mellitus; LILT, low level laser therapy

\section{Introduction}

Chronic periodontitis (CP) means inflammatory disorder that destroys the gingiva and is one of the most prevalent chronic dental infection of bacterial origin in adults affect about $90 \%$ of people and $22 \%$ of diabetic patients globally. ${ }^{1}$ Chronic periodontitis destroy the teeth supporting structures that lead to progressive alveolar bone and soft tissue destruction associated with gingival recession and formation of deep pocket. ${ }^{2}$

Poor glucose control associated with non-insulin dependent diabetes mellitus (NIDDM) is an important risk factor for CP and systemic inflammation. ${ }^{3,4}$ In the other hand $\mathrm{CP}$ which has a negative effect on glucose control. ${ }^{5}$ Moreover, systemic inflammatory associated with $\mathrm{CP}$ increased the risk of some disorders as renal failure, cardiovascular disorders and diabetes. ${ }^{6}$

Scaling and root planing (SRP) is a conventional therapy for $\mathrm{CP}$ associated with some limitations in managing deep periodontal pockets. $^{7}$ Therefore, many pharmacological adjuncts include antibiotics, anti-inflammatory and anticytokines were used to control inflammation and reduce bacterial. ${ }^{8-12}$ In addition, low level laser therapy (LILT) considered as an adjuncts to conventional therapy for CP. ${ }^{13}$ However, LILT Laser has excellent tissue ablation ability with a strong bactericidal effect as laser treatment improve the ability to access areas that are impossible to reach with conventional mechanical treatment. ${ }^{14-16}$ While, the accurate LLLT anti-inflammatory control mechanism of $\mathrm{CP}$ remains inconclusive. Therefore, this study aimed to assess the value of LILT added to SRP upon periodontal inflammation in NIDDM Saudi patients with CP.

\section{Patients and methods}

\section{Subjects}

Forty six NIDDM Saudi patients with chronic periodontitis (25 men and 21 women), their age ranged from 31-58 year (mean 41.2 \pm 5.17 year) were selected from the Department of Periodontics, King Fahd Hospital at Jeddah. Inclusion criteria included NIDDM patients with $\geq 4$ periodontal pockets and probing depth $\geq 5 \mathrm{~mm}$. However, exclusion criteria included smoking, autoimmune disorders, pregnancy, hemorrhagic disorders, acute illness, intake of anticoagulant, antibiotics and corticosteroid therapy during the 
previous three months. The participants randomly divided between 2 equal groups. Group (A) received conventional treatment for $\mathrm{CP}$ that composed of scaling and root planing (SRP group); while Group (B) received low intensity laser therapy conventional treatment for CP (SRP+LILT group).

\section{Measurements}

Periodontal parameters: Degree of periodontal indices were assessed by gingival index (GI) that was measured from 0 (indicated healthy gingiva) to 3 (indicated spontaneous bleeding, severe inflammation), the level of hygiene was assessed by plaque index (PI) that was measured from 1 (indicated presence of plaque detectable with probe) to 3 (abundant accumulation of plaque) and the pocket depth (PD) that measure the distance between base of the pocket and the free gingival margin, the values were converted into a score called T-score that was measured from 0 (PD ranged from 0 to $2 \mathrm{~mm}$ ) to 3 (PD>6mm). ${ }^{17-19}$

Biochemical parameters: From all participant an overnight fasting venous brachial blood sample was drained in clean test tube has few $\mathrm{ml}$ of K2EDTA for detection of glycosylated hemoglobin (HBA1c) using the standard colorimetric method with automated $\mathrm{HbAlc}$ analyzer (Quo-Lab® $\left.{ }^{\circledR} \mathrm{HbA1c}\right)$. In addition, ELISA kits were used for the measurement of tumor necrosis factor-alpha (TNF- $\alpha)$ and interleukin-6 (IL-6) levels in the gingival crevicular fluid samples (Diaclone SAS ${ }^{\circledR}$, Besançon, Bourgogne- Franche- Comté, France).$^{20}$

\section{Procedures}

The participants randomly divided between 2 equal groups

Group (A) : Twenty three NIDDM patients CP received conventional treatment for CP that composed of scaling and root planing (SRP group) to enhance periodontal tissue healing that included scaling that consisted of removal of tartar and plaque from supragingival and subgingival tooth surfaces mucobacterial by using inserts fixed on an ultrasonic scaler. However, root planning that consisted of removing granulation tissue, subgingival calculus deposits, infected \& necrotic cementum, in addition to abolishing root surface irregularities by using manual tools as curettes for 3 months.

Group (B): Twenty three NIDDM patients CP received conventional treatment for $\mathrm{CP}$ that composed of scaling and root planing in addition to low intensity laser therapy (LILT) (SRP+LILT group) using a $940 \mathrm{~nm}$ diode laser (ezlase ${ }^{\mathrm{TM}}$ soft tissue diode laser-Biolase Technology Inc.). Wave length was $940 \mathrm{~nm}$, application power was 3 $\mathrm{W}$, the optical diameter fiber and tips was $300-400 \mu$, pulse frequency was $15 \mathrm{~Hz}$, fluency was $1.2 \mathrm{~J} / \mathrm{mm}^{2}$, pulse duration and relaxation time equal 10 and 20 millisecond respectively for 3 months.

\section{Statistical analysis}

Comparison between mean values of the investigated before and after the study in both groups was calculated with Paired -ttest. However, comparison between groups was calculated with independent $-\mathrm{t}$ - test $(\mathrm{P}<0.05)$.

\section{Results}

Forty-six participants enrolled in group (A) received SRP $(n=23$; 13 males and 10 females), while group (B) received SRP + laser therapy ( $\mathrm{n}=23 ; 12$ males and 11 females). No statistical significant difference has been found between both groups regarding the criteria of participants (Table 1).

Mean values of TNF- $\alpha$, IL-6, HBA1c, Plaque index, Probing pocket depth and Gingival index reduced significantly after treatment in both groups (Table $2 \& 3$ ). However, comparison between both groups after treatment revealed significant differences between group (A) and group (B). Moreover, group (B) received SRP+ LILT gained greater reduction in the measured parameters (Table 4 ).

Table I Criteria of all participants

\begin{tabular}{llll}
\hline & $\begin{array}{l}\text { Mean+SD } \\
\text { Group (A) } \\
\text { (SRP group) }\end{array}$ & $\begin{array}{l}\text { Group (B) } \\
\text { (SRP + LILT group) }\end{array}$ & Significance \\
\hline Age (year) & $42.76 \pm 5.38$ & $41.92 \pm 5.16$ & $\mathrm{P}>0.05$ \\
Gender ratio (male/female) & $13 / 10$ & $12 / 11$ & $\mathrm{P}>0.05$ \\
BMI $\left(\mathrm{kg} / \mathrm{m}^{2}\right)$ & $31.65 \pm 1.73$ & $30.92 \pm 1.84$ & $\mathrm{P}>0.05$ \\
Fasting blood glucose $(\mathrm{mg} / \mathrm{dl})$ & $132.43 \pm 15.72$ & $134.16 \pm 14.51$ & $\mathrm{P}>0.05$ \\
Random blood glucose $(\mathrm{mg} / \mathrm{dl})$ & $191.57 \pm 17.38$ & $193.38 \pm 19.24$ & $\mathrm{P}>0.05$ \\
Duration of diabetes, years & $11.45 \pm 2.37$ & $10.12 \pm 2.81$ & $\mathrm{P}>0.05$ \\
Systoli c blood pressure $(\mathrm{mm} \mathrm{Hg})$ & $137.71 \pm 12.18$ & $139.23 \pm 11.75$ & $\mathrm{P}>0.05$ \\
Diastolic blood pressure $(\mathrm{mm} \mathrm{Hg})$ & $82.76 \pm 6.19$ & $83.94 \pm 6.65$ & $\mathrm{P}>0.05$ \\
\hline
\end{tabular}

BMI, Body mass index 
Table 2 Mean value and significance of TNF- $\alpha$, IL-6, HBAIc, PI , PD and GI in group (A) before and after treatment

\begin{tabular}{|c|c|c|c|c|}
\hline & $\begin{array}{l}\text { Mean+SD } \\
\text { Before }\end{array}$ & After & T- value & Significance \\
\hline TNF- $\alpha(p g / m l)$ & $5.86 \pm 1.47^{*}$ & $5.12 \pm 1.35^{*}$ & 3.56 & $P<0.05$ \\
\hline IL-6 (pg/ml) & $8.25 \pm 1.6 I^{*}$ & $7.13 \pm 1.39 *$ & 3.47 & $P<0.05$ \\
\hline HBAIc (\%) & $8.12 \pm 1.35 *$ & $7.24 \pm 1.3 I^{*}$ & 3.29 & $P<0.05$ \\
\hline Plaque index (percentage of sites) & $49.91 \pm 8.56$ & $31.15 \pm 5.2^{*}$ & 3.87 & $P<0.05$ \\
\hline Probing pocket depth (in millimeters) & $6.48 \pm 1.29$ & $4.61 \pm 1.12 *$ & 3.45 & $P<0.05$ \\
\hline Gingival index & $I .5 I \pm 0.35$ & $0.63 \pm 0.19 *$ & 3.31 & $P<0.05$ \\
\hline
\end{tabular}

TNF- $\alpha$, tumor necrosis factor - alpha; IL-6, Interleukin-6; HBA Ic, glycosylated hemoglobin; $\left(^{*}\right)$ indicates a significant difference between the two groups, $\mathrm{P}<0.05$

Table 3 Mean value and significance of TNF- $\alpha$, IL-6, HBA Ic, PI , PD and GI in group (B) before and after treatment

\begin{tabular}{lllll}
\hline & Mean+SD & & T- value & Significance \\
& Before & After & & \\
\hline TNF- $\alpha(\mathrm{pg} / \mathrm{ml})$ & $5.92 \pm 1.42$ & $4.7 I \pm 1.27^{*}$ & 6.31 & $\mathrm{P}<0.05$ \\
IL-6 $(\mathrm{pg} / \mathrm{ml})$ & $8.31 \pm 1.65$ & $6.15 \pm 1.42^{*}$ & 7.12 & $\mathrm{P}<0.05$ \\
HBA Ic $(\%)$ & $8.16 \pm 1.41$ & $6.34 \pm 1.25^{*}$ & 6.45 & $\mathrm{P}<0.05$ \\
Plaque index (percentage of sites) & $51.25 \pm 9.17$ & $20.78 \pm 3.26^{*}$ & 6.93 & $\mathrm{P}<0.05$ \\
Probing pocket depth (in millimeters) & $6.53 \pm 1.32$ & $3.11 \pm 1.14^{*}$ & 6.25 & $\mathrm{P}<0.05$ \\
Gingival index & $1.62 \pm 0.4 \mathrm{I}$ & $0.28 \pm 0.1 I^{*}$ & 6.34 & $\mathrm{P}<0.05$ \\
\hline
\end{tabular}

TNF- $\alpha$ : tumor necrosis factor - alpha; IL-6: Interleukin- 6 ; HBA I c: glycosylated hemoglobin; $(*)$ indicates a significant difference between the two groups, P < 0.05

Table 4 Mean value and significance of TNF- $\alpha$, IL-6, HBAIc, PI , PD and GI in group (A) and group (B) after treatment

\begin{tabular}{lllll}
\hline & Mean+SD & & T- value & Significance \\
& Group (A) & Group (B) & & \\
\hline TNF- $\alpha(\mathrm{pg} / \mathrm{ml})$ & $5.12 \pm 1.35$ & $4.71 \pm 1.27^{*}$ & 3.14 & $\mathrm{P}<0.05$ \\
IL-6 $(\mathrm{pg} / \mathrm{ml})$ & $7.13 \pm 1.39$ & $6.15 \pm 1.42^{*}$ & 4.11 & $\mathrm{P}<0.05$ \\
HBAIc $(\%)$ & $7.24 \pm 1.31$ & $6.34 \pm 1.25^{*}$ & 3.26 & $\mathrm{P}<0.05$ \\
Plaque index (percentage of sites) & $31.15 \pm 5.23$ & $20.78 \pm 3.26^{*}$ & 3.34 & $\mathrm{P}<0.05$ \\
Probing pocket depth (in millimeters) & $4.61 \pm 1.12$ & $3.11 \pm 1.14^{*}$ & 3.25 & $\mathrm{P}<0.05$ \\
Gingival index & $0.63 \pm 0.19$ & $0.28 \pm 0.1 I^{*}$ & 3.28 & $\mathrm{P}<0.05$ \\
\hline
\end{tabular}

TNF- $\alpha$, tumor necrosis factor - alpha; IL-6, Interleukin-6; HBA Ic, glycosylated hemoglobin; $(*)$ indicates a significant difference between the two groups, P < 0.05

\section{Discussion}

Periodontal diseases are 2.8 times more among diabetic patients with hyperglycemia about 5 times higher risk of oral infections than non-diabetic subjects. ${ }^{21}$ However, CP is the $6^{\text {th }}$ complication of diabetes. ${ }^{22}$ In the other hand, periodontal therapy improves metabolic control in diabetics. ${ }^{23}$ Our study aimed to assess the value of LILT added to SRP upon periodontal inflammation in NIDDM Saudi CP patients. The outcomes of our study proved that SRP added to LLLT significantly reduced the GCF levels of TNF- $\alpha$ and IL- 6 greater than SRP alone in NIDDM patients with CP, these findings agreed with many studies. Sun et al. stated that conventional treatment improved inflammatory cytokines in NIDDM patients with $\mathrm{CP}^{24}$ However,
Kocak et al. ${ }^{25}$ proved that adjunct LLLT to SRP significantly reduced GCF IL-6 with no significant change in GCF IL-8 among NIDDM patients with $\mathrm{CP} .{ }^{25}$ While, Calderin et al ${ }^{26}$ reported that 2 months of adjunct LLLT to SRP significantly reduced GCF TNF- $\alpha$ in patients with CP. Also, Gundogar et al. ${ }^{27}$ and Üstün et al. ${ }^{28}$ mentioned that adjunct LLLT to SRP significantly reduced GCF cytokines in patients with CP. Moreover, Lee et al. ${ }^{29}$ mentioned that LLLT significantly reduced the pro-inflammatory genes expression in periodontal inflammatory disease. ${ }^{29}$ In the other hand, Kellesarian et al. ${ }^{30}$ conducted a systematic review on 22 randomized control trials and reported that the impact of adjunct LLLT to SRP upon pro-inflammatory cytokines expression in $\mathrm{CP}$ patients was inconclusive. 
Concerning the periodontal parameters, the study results showed a significantly reduced Plaque index, Probing pocket depth and Gingival index that indicated improvement in periodontal wound healing after 3 months of SRP adjuvant LLLT which agreed with Ustun et al. ${ }^{31}$ reported that $810 \mathrm{~nm}$ diode laser can cause significant reduction in GCF and IL-1 $\beta$ compared to control group, which could be an explanation for the decrease in GI and PD. However, DemirturkGocgun et $\mathrm{al}^{32}$ found significant improvement in PI and PD one month following SRP adjuvant LLLT in patients with NIDDM. While, Crispino et al. ${ }^{33}$ mentioned that diode LILT in addition to SRP was associated with more evident results in periodontal parameters (GI, PI and PD) of CP patients. Moreover, Obradović et al..$^{34}$ proved that LLLT improved healing of gingival tissue as evident of histologic findings and absence of inflammatory cells

Regarding glycemic control, our findings revealed significantly reduced level of HBA1c that indicated improvement in glycemic control after 3 months of scaling and root planing, adjuvant LLLT, while many studies indicated that periodontal therapy resulted in low level of HBA1c in NIDDM patients. ${ }^{35-37}$ While, Stewart et al. ${ }^{35}$ stated that nine months of periodontal treatment significantly improved glucose control in NIDDM patients. ${ }^{38}$ However, Yun et al. ${ }^{39}$ reported reduction in glycated hemoglobin (HbAlc), plaque index and bleeding on probing scores after 16 weeks of SRP in 46 NIDDM patients with CP. ${ }^{39}$ Similarly, Botero et al. ${ }^{40}$ mentioned that their systematic review proved that 3 months of periodontal treatment in NIDDM patients with CP. Moreover, Kocak et al. ${ }^{41}$ proved that 3 months of LILT in addition to SRP significantly reduced HbAlc in type 2 diabetics with periodontitis.

The possible mechanisms for the positive effects of combining laser therapy with SRP were achieved via more effective decontamination and slower recolonization of the pocket. ${ }^{42-44}$ However, the curettage effect of laser ensure complete removal of infected sulcular epithelium. ${ }^{45,46}$ While, infected granulation tissue removal induce connective tissue healing that minimize the GI and PD. ${ }^{47-51}$ In addition to the diode laser antimicrobial effect that kills the periodontal microorganism..$^{51}$ In the other hand, laser accelerates mitochondrial production of adenosine triphosphate (ATP) through respiratory chain system biomodulative effect which induce halving of cell duplication times. ${ }^{52,53}$

\section{Conclusion}

Low intensity laser therapy as an effective adjunct to periodontal therapy upon periodontal inflammation in NIDDM Saudi patients with CP.

\section{Funding}

None.

\section{Acknowledgments}

None.

\section{Conflicts of interest}

Author declares that there is no conflict of interest.

\section{References}

1. Cullinan MP, Ford PJ, Seymour GJ. Periodontal disease and systemic health: current status. Aust Dent J. 2009;54:1S62-S69.
2. Papapanou PN, Sanz M, Buduneli N, et al. Greenwell, Periodontitis: consensus report of workgroup 2 of the 2017 world workshop on the classification of periodontal and peri $\square$ implant diseases and conditions. J Periodontol. 2018;89:S173-S82.

3. Taylor JJ, Preshaw PM, Lalla E, et al. A review of the evidence for pathogenicmechanisms that may link periodontitis and diabetes. $J$ Clin Periodontol. 2013;40 Suppl 14:S113-S134.

4. Preshaw PM, Alba AL, Herrera D, et al. Periodontitis and diabetes: a two-way relationship, Diabetol. 2012;55(1):21-31.

5. Loe H. Periodontal disease. The sixth complication of diabetes. Diabetes Care. 1993;16(1):329-334.

6. D'Aiuto F, Gkranias N, Bhowruth D, et al. Systemic effects of periodontitis treatment in patients with type 2 diabetes: a 12 month, single-centre, investigator-masked, randomised trial. Lancet Diabetes Endocrinol. 2018;6(12):954-965.

7. Cobb CM. Clinical significance of non-surgical periodontal therapy: an evidence-based perspective of scaling and root planning. $J$ Clin Periodontol. 2002;29 Suppl 2:6-16.

8. Agossa K, Morand DN, Tenenbaum H, et al. Systemic application of anti-inflammatory agents in periodontal treatment. Clinical AntiInflammatory \& Anti-Allergy Drugs. 2016;2(1):3-13.

9. Akram Z, Abduljabbar T, Kellesarian SV, et al. Efficacy of bisphosphonate as an adjunct to nonsurgical periodontal therapy in the management of periodontal disease: a systematic review. $\mathrm{Br} \mathrm{J} \mathrm{Clin}$ Pharmacol. 2017;83(3):444-454.

10. Alshammari A, Patel J, Al-Hashemi J, et al. "Kava-241 reduced periodontal destruction in a collagen antibody primed Porphyromonas gingivalis model of periodontitis. J Clin Periodontol. 2017;44(11):11231132 .

11. Gokhale SR, Padhye AM. Future prospects of systemic host modulatory agents in periodontal therapy. British Dental Journal. 2013;214(9):467471.

12. Martin-Cabezas R, Davideau JL, Tenenbaum H, et al. Clinical efficacy of probiotics as an adjunctive therapy to non-surgical periodontal treatment of chronic periodontitis: a systematic review and meta-analysis. Journal of Clinical Periodontology. 2016;43(6):520-530.

13. Gundogar H, Senyurt SZ, Erciyas K, et al. The effect oflow-level laser therapy on non-surgical periodontal treatment: a randomizedcontrolled, single-blind, split-mouth clinical trial. Lasers Med Sci. 2016;31(9):17671773 .

14. Farivar S, Malekshahabi T, Shiari R. Biological effects of low level laser therapy. J Lasers Med Sci. 2014;5(2):58-62.

15. Caruso U, Nastri L, Piccolomini R, et al. Use of diode laser $980 \mathrm{~nm}$ as adjunctive therapy in the treatment of chronic periodontitis. A randomized controlled clinical trial. New Microbiol. 2008;31(4):513-518.

16. Convissar RA. Principles and practice of laser dentistry: Elsevier Health Sciences; 2015. 328 p.

17. Bortone F, Santos HA, Albertini R, et al. Low level laser therapy modulates kinin receptors mRNA expression in the subplantar muscle of rat paw subjected to carrageenan-induced inflammation. Int Immunopharmacol. 2008;8(2):206-210.

18. Obradovic R, Kesic L, Mihailovic D, et al. A histological evaluation of a low level laser therapy as an adjunct to periodontal therapy in patients with diabetes mellitus. Lasers Med Sci. 2013;28(1):19-24.

19. Crispino A, Figliuzzi MM, Iovane C, et al. Effectiveness of a diode laser in addition to non-surgical periodontal therapy: study of intervention. Ann Stomatol (Roma). 2015;6(1):15-20. 
20. Segarra-Vidal M, Guerra-Ojeda S, Vallés LS, et al. Effects of photodynamic therapy in periodontal treatment: A randomized, controlled clinical trial. J Clin Periodontol. 2017;44(9):915-925.

21. Soskolne WA, Klinger A. The relationship between periodontal diseases and diabetes: an overview. Ann Periodontol. 2001;6(1):91-98.

22. Loe H. Periodontal disease: the sixth complication of diabetes mellitus. Diab Care. 1993;16(1):329-334.

23. Al Mubarak S, Rass MA, Alsuwyed A, et al. A new paradigm between mechanical scaling and root planing combined with adjunctive chemotherapy for glycated hemoglobin improvement in diabetics. Int $J$ Diab Mellitus. 2010;2(3):158-164.

24. Sun WL, Chen LL, Zhang SZ, et al. Inflammatory cytokines, adiponectin, insulin resistance and metabolic control after periodontal intervention in patients with type 2 diabetes and chronic periodontitis. Intern Med. 2011;50(15):1569-1574.

25. Kocak E, Saglam M, Kayis SA, et al. Nonsurgical periodontal therapy with/without diode laser modulates metabolic control of type 2 diabetics with periodontitis: a randomized clinical trial. Lasers Med Sci. 2016;31(2):343-353.

26. Calderin S, Garcia-Nunez JA, Gomez C, et al. Short-term clinical and osteoimmunological effects of scaling and root planing complemented by simple or repeated laser phototherapy in chronic periodontitis. Lasers Med Sci. 2013;28(1):157-166.

27. Gundogar H, Senyurt SZ, Erciyas K, et al. The effect of low-level laser therapy on non-surgical periodontal treatment: a randomized controlled, single-blind, split-mouth clinical trial. Lasers Med Sci. 2016;31(9):1767-1773.

28. Ustun K, Erciyas K, Sezer U, et al. Clinical and biochemical effects of $810 \mathrm{~nm}$ diode laser as an adjunct to periodontal therapy: a randomized split-mouth clinical trial. Photomed Laser Surg. 2014;32(2):61-66.

29. Lee JH, Chiang MH, Chen PH, et al. Anti-inflammatory effects of lowlevel laser therapy on human periodontal ligament cells: in vitro study. Lasers Med Sci. 2018;33(3):469-477.

30. Kellesarian SV, Malignaggi VR, Majoka HA, A et al. Effect of laserassisted scaling and root planing on the expression of pro-inflammatory cytokines in the gingival crevicular fluid of patients with chronic periodontitis: A systematic review. Photodiagnosis Photodyn Ther. 2017;18:63-77.

31. Ustun K, Erciyas K, Sezer U, et al. Clinical and biochemical effects of $810 \mathrm{~nm}$ diode laser as an adjunct to periodontal therapy: a randomized split-mouth clinical trial. Photomed Laser Surg. 2014;32(2):61-66.

32. Demirturk-Gocgun O, Baser U, Aykol-Sahin G, et al. Role of Low-Level Laser Therapy as an Adjunct to Initial Periodontal Treatment in Type 2 Diabetic Patients: A Split-Mouth, Randomized, Controlled Clinical Trial. Photomed Laser Surg. 2017;35(2):111-115.

33. Crispino A, Figliuzzi MM, Iovane C, et al. Effectiveness of a diode laser in addition to non-surgical periodontal therapy: study of intervention. Ann Stomatol (Roma). 2015;6(1):15-20.

34. Obradović R, Kesić L, Mihailović D, et al. A histological evaluation of a low-level laser therapy as an adjunct to periodontal therapy in patients with diabetes mellitus. Lasers Med Sci. 2013;28(1):19-24.

35. Kiran M, Arpak N, Unsal E, et al. Effect of improved periodontal health on metabolic control in T2DM. J Clin Periodontol. 2005;32(3):266-272.

36. Navarro-Sanchez AB, Faria-Almeida R, Bascones-Martinez A. Effect of non-surgical periodontal therapy on clinical and immunological response and glycemic control in type 2 diabetic patients with moderate periodontitis. J Clin Periodontol. 2007;34(10):835-843.
37. Koromantzos PA, Makrilakis K, Dereka X, et al. A randomized, controlled trial on the effect of non-surgical periodontal therapy in patients with type 2 diabetes. Part I: effect on periodontal status and glycemic control. J Clin Periodontol. 2011;38(2):142-147.

38. Stewart JE, Wager KA, Friedlander AH, et al. The effect of periodontal treatment on glycemic control in patients with type 2 diabetes mellitus. J Clin Periodontol. 2001;28(4):306-310.

39. Yun D, Firkova EI, Lin JQ, et al. Effect of non-surgical periodontal therapy on patients with type 2 diabetes mellitus. Folia Med (Plovdiv). 2007;49(1-2):32-36

40. Botero JE, Rodríguez C, Agudelo-Suarez AA. Periodontal treatment and glycaemic control in patients with diabetes and periodontitis: an umbrella review. Aust Dent J. 2016;61(2):134-148.

41. Koçak E, Sağlam M, Kayış SA, et al. Nonsurgical periodontal therapy with/without diode laser modulates metabolic control of type 2 diabetics with periodontitis: a randomized clinical trial. Laser Med Sci. 2016;31(2):343-353.

42. Moritz A, Gutknecht N, Doertbudak O, et al. Bacterial reduction in periodontal pockets through irradiation with a diode laser: a pilot study. J Clin Laser Med Surg. 1997;15(1):33-37.

43. Moritz A, Schoop U, Goharkhay K, et al. Treatment of periodontal pockets with a diode laser. Lasers Surg Med. 1998;22(5):302-311.

44. Saglam M, Kantarci A, Dundar N, et al. Clinical and biochemical effects of diode laser as an adjunct to nonsurgical treatment of chronic periodontitis: a randomized, controlled clinical trial. Lasers Med Sci. 2014;29(1):37-46

45. Kamma JJ, Vasdekis VG, Romanos GE. The effect of diode laser ( 980 $\mathrm{nm})$ treatment on aggressive periodontitis: evaluation of microbial and clinical parameters. Photomed Laser Surg. 2009;27(1):11-19.

46. Kreisler M, Al Haj H, d'Hoedt B. Clinical efficacy of semiconductor laser application as an adjunct to conventional scaling and root planing. Lasers Surg Med. 2005;37(5):350-355.

47. Angelov N, Pesevska S, Nakova M, et al. Periodontal treatment with a low-level diode laser: clinical findings. Gen Dent. 2009;57(5):510-513.

48. Caruso U, Nastri L, Piccolomini R, et al. Use of diode laser $980 \mathrm{~nm}$ as adjunctive therapy in the treatment of chronic periodontitis. Arandomized controlled clinical trial. New Microbiol. 2008;31(4):513-518.

49. Giannelli M, Formigli L, Lorenzini L, et al. Combined photoablative and photodynamic diode laser therapy as an adjunct to non-surgical periodontal treatment. A randomized splitmouth clinical trial. J Clin Periodontol. 2012;39(10):962-970.

50. Pejcic A, Kojovic D, Kesic L, et al. The effects of low level laser irradiation on gingival inflammation. Photomed Laser Surg. 2010;28(1):69-74.

51. Gojkov-Vukelic M, Hadzic S, Dedic A, et al. Application of a diode laser in the reduction of targeted periodontal pathogens. Acta Inform Med. 2013;21(4):237-240.

52. Passarella S, Casamassima E, Molinari S, et al. Increase of proton electrochemical potential and ATPsynthesis in rat liver mitochondria irradiated in vitro by helium-neon laser. FEBS Lett. 1984;175(1):95-99.

53. Benedicenti S, Pepe IM, Angiero F, et al. Intracellular ATP level increases in lymphocytes irradiated with infrared laser light of wavelength 904 nm. Photomed Laser Surg. 2008;26(5):451-453. 